\title{
Measuring road space consumption by transport modes: Toward a standard spatial efficiency assessment method and an application to the development scenarios of Rajkot City, India
}

\author{
Marie-Eve Will \\ DTU Management Engineering \\ marie.eve.will@gmail.com
}

\author{
Yannick Cornet \\ University of Žilina \\ yannick.cornet@uniza.sk
}

\section{Talat Munshi \\ DTU Management Engineering \\ tamu@dtu.dk}

\begin{abstract}
The space "consumed" by various urban passenger transport modes varies greatly depending on the size and the speed of vehicles. Past studies have shown that public transport (PT) and non-motorized transport (NMT) can be up to 20 times more space-efficient compared to a typical car. This optimal use of space is of relevance in an urban context where space is often a constrained resource. Yet space used by vehicles is rarely assessed in the practice of transport planning. There exists no standard method for quantifying the use of space in complex urban settings. This study proposes an approach based on the spacetime concept for quantifying and comparing the dynamic (on-road) and still (parking) space used by different transport modes for a specific road network. Transport planning scenarios developed in the Lowcarbon Comprehensive Mobility Plan (LCMP) prepared for the city of Rajkot are used to demonstrate the method. The indicators show that significantly less space is used by transport in a scenario that promotes higher use of PT and NMT in comparison to a business-as-usual scenario based on traffic projections for private motorized vehicles. These results provide evidence that could contribute to alleviating chronic congestion expected from car- and motorcycle-based transport development only. Overall, this research describes an assessment framework for low-carbon transport development that would include spatial efficiency concerns.
\end{abstract}

\section{Introduction: passenger transport and urban space consumption}

Transport infrastructure provides the means for residents to access their desired activity locations, which in turn shapes spatial patterns of development (Banjo \& Dimitriou, 1983; Dimitriou, 2006; Geurs, 2006; Munshi \& Brussel, 2004; Wegener \& Fürst,

\section{Article history:}

Received: February 1, 2019

Received in revised form: July

20, 2020

Accepted: July 20, 2020

Available online: November 23,

2020

Copyright 2020 Marie-Eve Will, Yannick Cornet \& Talat Munshi

http://dx.doi.org/10.5198/jtlu.2020.1526

ISSN: 1938-7849 | Licensed under the Creative Commons Attribution - Noncommercial License 4.0

The Journal of Transport and Land Use is the official journal of the World Society for Transport and Land Use (WSTLUR) and is published and sponsored by the University of Minnesota Center for Transportation Studies. 
1999). Road-based transport infrastructure networks (highways, collector roads, urban arteries, and parking lots) typically account for a relatively large share of urban space; therefore the efficient use of road space and the reallocation of space to other uses are seen as crucial interventions in the global debate around the role of transport in low-carbon transitions (Banister, 2008; Hickman, Ashiru, \& Banister, 2011; Kivimaa \& Virkamäki, 2014; von Schönfeld \& Bertolini, 2017). In practice, infrastructure choices can lead to long-term lock-ins in terms of transport choices (Munshi, \& Zia-ul-Haque, 2016; Unruh \& Carrillo-Hermosilla, 2006). For example, adapting road supply to accommodate an increase in car traffic can lead to more vehicles on the road and create more traffic in the long term (Dimitriou, 2006; Metz, 2008). Trends of increasing individual motorized vehicle ownership promote more caroriented transport planning, stigmatizing and reducing the use of other modes, which in turn further entrenches the path towards suburbanization, car-based land use planning, urban sprawl and finally further increases in vehicle ownership. Previous (but scarce) studies on the spatial footprint of various transport modes have shown public and non-motorized transport can be up to 20 times more spaceefficient per passenger than a typical car (Héran \& Ravalet, 2008). A shift from car to public transport (PT) and non-motorized transport (NMT) can therefore theoretically contribute to freeing up precious city space (Gössling et al., 2016).

In developing countries, a significant portion of the lower-income population depends on public transport and non-motorized transport. Typical to many other developing countries, India has traditionally been known for limited transport infrastructure provision, with demand levels often overwhelming the transport infrastructure supply (Pucher, Korattyswaropam, Mittal, \& Ittyerah, 2005; Tiwari, 2011). Transport planners have mainly focused on reducing road congestion and on accommodating the everincreasing number of motorized vehicles. Transport planning thus far has therefore favored the use of cars (Tiwari, 2011). There has been a general failure to incorporate NMT in the transport planning process, and PT plans and provisions are inadequate and not comprehensive (Munshi, 2013). Despite insufficient infrastructure provision, walking, bicycles, rickshaws, public transport as well as motorized paratransit still dominate urban transport in India. However, most of NMT and PT users are captive users, unable to afford using other modes. The National Urban Transport Policy (MOUD, 2006) stresses the relevance of promoting NMT and PT modes to retain the existing users and possibly entice present private motorized vehicle users to shift to NMT and PT modes. Providing safe and dedicated infrastructures for NMT and PT modes is crucial in bringing individuals to deliberately choosing these modes (Munshi, Maarseveen, \& van Zuidgeest, 2013; Oldenziel \& Albert de la Bruhèze, 2011).

This paper presents a methodology for the spatial assessment of transport modes with an overall goal to improve spatial efficiency. Section 2 starts by outlining how the proposed assessment framework draws from previous transport spatial assessment studies. In section 3, the detailed methodology developed to quantify space is presented for both moving traffic and parking. In section 4, measures for different transport modes are presented for each of the Rajkot's development scenarios. Spatial efficiency measures are further illustrated for a $1 \mathrm{~km}$ road section. Suggested improvements to the methodology and conclusions are presented in the last section.

\section{Scope and assumptions}

The UN-Environments Promoting Low Carbon Transport project in India (2010-2014) aimed to tighten the synergy between India's national climate change policy and efforts to develop and improve urban transport systems. The project assessed transport mobility for business-as-usual scenario (BAU) and Low-carbon Comprehensive Mobility Plan (LCMP) scenarios for three case cities in India: Ra- 
jkot, Vishakhapatnam and Udaipur. The business-as-usual scenario predicts travel demand for the year 2031 assuming urban development, economic growth and motorization follow current trends. The low carbon scenario includes land-use changes aimed at organizing the urban development around nodes with high job and housing densities, and other measures to encourage higher use of non-motorized and public transport modes as well as shorter travel distances.

The city of Rajkot, this paper's demonstration case, is a second-tier Indian city located in the state of Gujarat in western India. Its estimated metropolitan area population is 1.2 million inhabitants. Rajkot city's central area was constructed in the 18th century and is characterized by narrow lanes originally designed for travel using non-motorized modes. The outer part of the city, which has developed more recently, is following a car-oriented development pattern. As the city is still growing, there is a possibility to learn from the evolution and planning trends in Western cities and potentially leapfrog the caroriented planning phase to a more sustainable urbanism phase. This paper furthers the traffic modelling work done for Rajkot and evaluates the space used by transport in three configurations: the situation as of 2011, and two different transport development scenarios for year 2031, a BAU and a LCMP scenario (Munshi et al., 2014).

In the literature, the quantification of the space used by transport, both for street networks and public parking facilities, can be found in a handful of studies. Apel (2000) conducted a comparative study on the structure of the cities of Oldenburg (Germany), Delft (The Netherlands), and Denver (USA). By estimating the space used by streets and transport facilities, the research shows how car-based transport planning acts as a major cause for the expansion of settlement space. It suggests that specific transport infrastructure characteristics, as well as population and job density distributions, would enable a reduction in the need for new settlement space. One strand of transport literature more concerned with the spatial consumption of various modes is the literature on parking, where physical footprint estimates are used to improve parking charges policies (Shoup, 2006).

More recently, a case-study of Fribourg (Germany) put emphasis on the differences in space allocation between modes and the fairness issues implied (Gössling et al., 2016). The space dedicated to different mode categories in four neighborhoods of the city planned at different periods in history is measured through high-resolution satellite images, for Wiehre and Herdern (1900s), Weingarten (1960s), and Vauban (1990s). Without taking private parking into account, the study shows that between 45 and $60 \%$ of available transport infrastructure space is allocated to roads and public parking, with pedestrian areas, public transport lanes, bicycle lanes, and other mixed-use spaces sharing the remaining available space (in this descending order). The research illustrates how differences between neighborhood designs epitomize the urban and transport planning trends of their respective construction period (Gössling et al., 2016). Implications of different measures of space distribution between modes on social fairness is further reflected in the recent contribution by Nello-Deakin (2019), and a study in France operationalized the concept of road space consumption to illustrate the potential benefits of a shift towards shared transportation modes (Drut, 2018).

Similarly to Drut (2018), this paper draws mainly from the study by Héran and Ravalet (2008) where the space consumed by travelers on different modes was theorized and quantified for the city of Paris. In the Héran and Ravalet study, the quantification of spatial consumption was based on daily travel diaries from household surveys. As the use of space varies with time, the assessment resorts to a dynamic indicator measuring space-time consumed per trip. In their study, traffic and parking space calculation are calibrated based on the space allocated to road and parking infrastructures.

In this paper, traffic and parking space consumption estimates are further refined by using actual vehicle sizes, numbers and speeds. The methodology for this paper was also tuned to represent the reality on the ground in Rajkot: in India, traffic and parking are more compact than in western cities. Several vehicles may occupy the same lane width on the road, especially motorized two-wheelers which 
tend to slot into every available space. Similarly, parking, for the significant part, does not take place in predefined parking spots.

Figure 1 illustrates how key references contribute to the proposed method used in this paper.

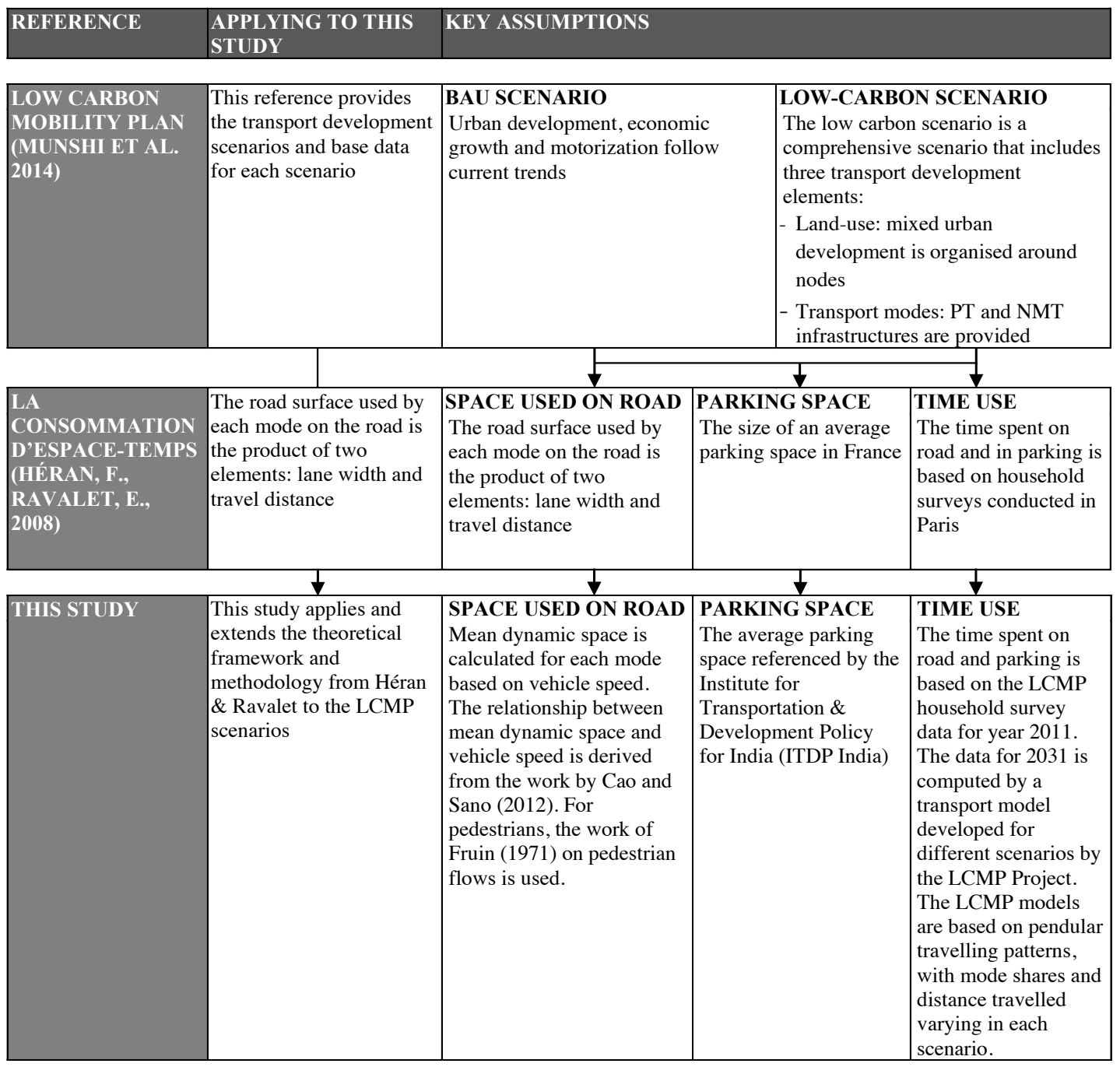

Figure 1. Key references and assumptions used in the study

\section{$3 \quad$ Methodology}

\subsection{Overview}

The methodology developed (Figure 2) aims at quantifying the space-time used by passenger transport modes, both for parking and on-road, and is extended to the BAU and LCMP scenarios forecasts. Applying space-time measurements on future transport development scenarios is the main methodological contribution of this paper.

The travelling space-time and the parking space-time indicators flow from the LCMP project scenarios, which included household surveys and future transport demand projections. The LCMP 
transport model predicted the urban area's socio-economic and land-use transitions (Munshi et al., 2014). Household surveys consisted of revealed and stated preference surveys, enabling the forecasting of mode-choice and distance travelled changes as a result of new infrastructure provision. The model was developed for 2011 and calibrated using on-the-ground traffic surveys at cordons, screen lines and important junctions. In the LCMP project, the traditional four-step modelling approach was adapted by using small traffic analysis zones and a modelling method that allowed determining mode shares for non-motorized modes (walking and bicycling) and auto-rickshaws, as well as assigning these trips to roads.

Travel demand is the primary input of the space-time consumption indicator. Rajkot is divided into 23 wards, for which space-time used by transport is calculated and then aggregated into a city-level indicator. The indicator measures the space-time consumed per day for travelling and parking by modes and scenario. The space-time used by transport is estimated for the base-year 2011, as well as for two transport development scenarios for the year 2031, BAU and LCMP. Space-time calculations includes all types of trips (and not only work-related trips).

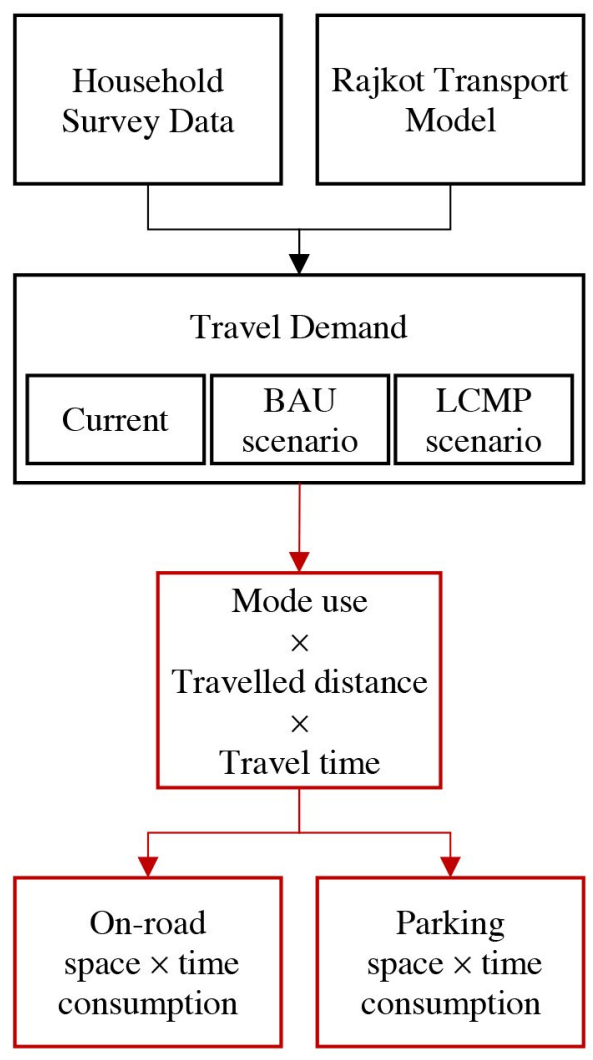

Figure 2. Transport space-time consumption; outlined in black: input data from previous studies (Munshi et al., 2014); in red: methodology for space-time consumed by transport developed for this research

In this study, when considering on-road and parking space-times, space-time is expressed in $\mathrm{km}^{2}$. day (or in $\mathrm{km}^{2}$.h): this is to take into account that the space used travelling or parking concerns a specific time-fraction of the day. However, when the travelling space-time is aggregated to the parking spacetime over a single day, the total time fraction becomes one day (vehicles are either travelling or parking). Aggregating travelling and parking space-time indicators over a single unit of time, (such as a full day or 
one hour) results in an indicator that can be expressed in $\mathrm{km}^{2}$ and assimilated to a purely spatial indicator. The model used in the present paper is based on daily travel patterns, this enables to conflate space and space-time when considering aggregated indicators that combine travelling with parking spacetimes over a day.

\subsection{Transport development scenarios: input parameters}

Relevant input parameters for the 2031 LCMP and BAU scenarios taken from the Rajkot LCMP report (Munshi et al., 2014) are presented in Table 1 below.

Table 1. Input parameters for the $2031 \mathrm{BAU}$ and LCMP transport development scenarios

\begin{tabular}{|c|c|c|}
\hline Variables & BAU 2031 & LCMP 2031 \\
\hline \multirow[t]{3}{*}{ Modal shares } & NMT $-29 \%$ & NMT $-44 \%$ \\
\hline & $\mathrm{PT}-11 \%$ & $\mathrm{PT}-29 \%$ \\
\hline & Private Automobile- 57\% & Private Automobile - $27 \%$ \\
\hline Average travel time (min) & 27 & 16 \\
\hline Average trip length $(\mathrm{km})$ & 6.0 & 3.9 \\
\hline \multirow[t]{4}{*}{ Floor Area Ratio (FAR) and density } & FAR: 1.8 & $\begin{array}{l}\text { FAR Major and Minor roads }(500 \mathrm{~m} \\
\text { buffer): } 4.0\end{array}$ \\
\hline & & Along the BRTS corridor $(500 \mathrm{~m}$ \\
\hline & & buffer): 3.0 \\
\hline & & Rest of the city: 1.2 \\
\hline \multirow{4}{*}{$\begin{array}{l}\text { Land use mix intensity (entropy index } \\
\text { calculated as in (Munshi, 2013)) }\end{array}$} & 0.34 (Mean across the city) & City Centre: 0.80 \\
\hline & & Major nodes: 0.75 \\
\hline & & Minor nodes: 0.50 \\
\hline & & Corridors: 0.40 \\
\hline New dwelling units & 0.264 million & $\begin{array}{l}0.264 \text { million (but different spatial } \\
\text { distribution) }\end{array}$ \\
\hline Number of households & 0.78 million & 0.78 million \\
\hline Additional land consumption & $102.55 \mathrm{Sq} . \mathrm{km}$ & $58.49 \mathrm{Sq} \cdot \mathrm{km}$ \\
\hline \multirow[t]{2}{*}{ Vehicle ownership } & Private Automobile (1.03 million) & Private Automobile ( 0.57 million) \\
\hline & Bicycles ( 0.21 million) & Bicycles (0.35 million) \\
\hline \multirow[t]{4}{*}{ Vehicle occupancy (users/vehicle) } & Motorized two-wheelers: 1,2 & Motorized two-wheelers: 1,2 \\
\hline & Buses: 34 & Buses: 34 \\
\hline & Cars: 1,3 & Cars: 1,3 \\
\hline & Auto-rickshaws: 1,2 & Auto-rickshaws: 1,2 \\
\hline Total road length & $2776 \mathrm{~km}$. & $2470 \mathrm{~km}$. \\
\hline$\%$ of road with $>2 \mathrm{~m}$ footpath & $8 \%$ & $35 \%$ \\
\hline$\%$ of roads lightened & $83 \%$ & $88 \%$ \\
\hline$\%$ of footpath lightened & $35 \%$ & $100 \%$ \\
\hline$\%$ of roads with cycle lanes & $1.7 \%$ & $10 \%$ \\
\hline$\%$ of roads with dedicated bus lanes & $3 \%$ & $11 \%$ \\
\hline \multirow[t]{2}{*}{ Bus fleet } & 324 (42 seats) & 675 (42 seats) \\
\hline & & 1443 minibuses (18 seats) \\
\hline \multirow[t]{2}{*}{ Headways } & Irregular, peak hour around 30 & Peak hour -2.5 minutes on the BRTS \\
\hline & minutes. & corridor, 5-20 minutes on other routes \\
\hline
\end{tabular}


The BAU scenario assumes that transport infrastructure development will follow past growth patterns. The LCMP scenario illustrated in Figure 3 proposes a Bus Rapid Transit Service (BRTS) along the main transport corridors of the city and transit-oriented development along these routes. In this scenario the bus fleet size is significantly increased from 326 buses to 675 standard buses and 1143 minibuses. Major nodes and minor nodes are proposed with a high Floor Area Ratio (FAR: the ratio of a building's total floor area to the size of the piece of land upon which it is built) to promote high density and mixed land use around the transit nodes. In addition, dedicated bicycle paths development and footpath upgrades are also proposed across the city (Figure 3). The LCMP study conducted a stated preference survey to compare mode choice for both the 2031 BAU and LCMP scenarios. It is expected that a significant share of travelers will opt for PT and NMT modes once proper infrastructures are provided, which translates in a reduction of private automobile ownership in the 2031 LCMP scenario compared to the 2031 BAU scenario.

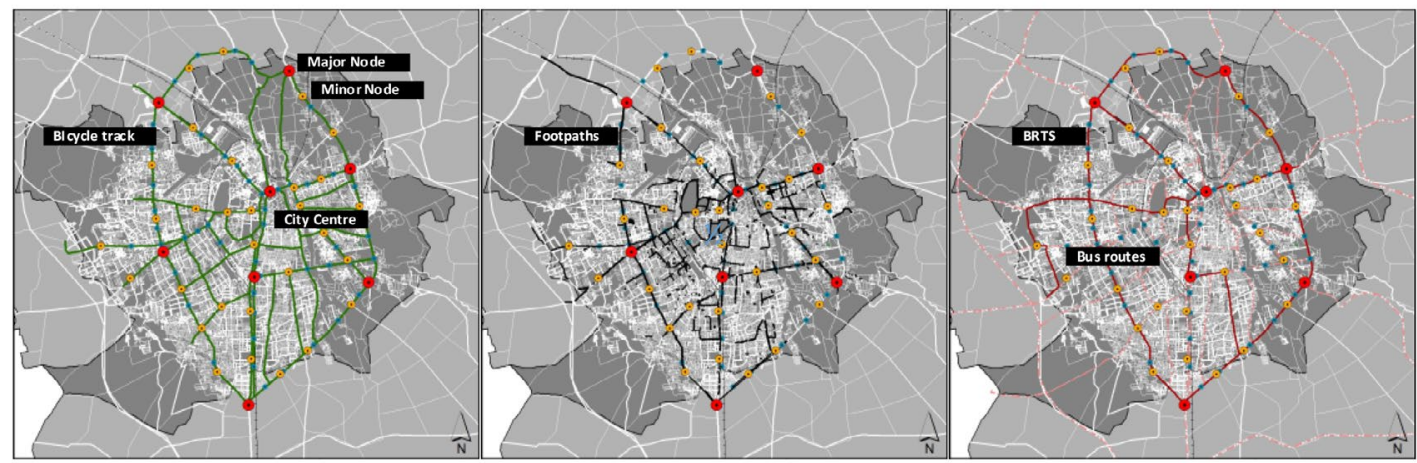

Figure 3. 2031 LCMP proposed transport infrastructure for the city of Rajkot

\subsection{Space-time used on-road}

The space-time indicator applies the concept developed by Héran and Ravalet (2008) to the specific case of Rajkot and combines both current and projected trip data for the transport development scenarios. Four main variables have been defined to assess the space-time used on-road (Figure 4):

- Number of vehicles of mode $x$ on a road segment $a b, N_{a b}^{x}$

- Space used by a vehicle of mode $x$ at a mean speed $\bar{v}_{x}, \bar{s}_{x}$

- Time spent by vehicles of mode $x$ on a road segment $a b, t_{a b}^{x}$

- Overall space-time consumed by vehicles of mode $x$ in a ward $I, \alpha_{I}^{x}$

\subsubsection{Number of on-road vehicles}

The number of vehicles on-road is obtained from the transport model, which produces daily passenger trips (which were validated for the BAU scenario using on-ground traffic counts). The number of vehicles on each road segment is obtained by dividing the latter with vehicle occupancy ratios, available for Ahmedabad (Munshi, 2013). Vehicle occupancy ratios are taken from a study on built form and travel behavior in Ahmedabad, India by Munshi (2013). The number of vehicles of mode x on road segment $\mathrm{ab}$ is given by: 
$N_{a b}^{x}=\frac{f_{a b}^{x}}{R_{x}}$

Where $N_{a b}^{x}$ is the number of vehicles of mode $x$ on road segment $a b, f_{a b}^{x}$ is the daily passenger trips travelled by mode $x$ on road segment $a b$, and $R_{x}$ the occupancy ratio of a vehicle of mode $x$.

\subsubsection{Space used by the different vehicles}

The space used on-road by moving vehicles increases with speed: the dynamic space for a moving vehicle is the safe space required to maintain the desired speed. The relationship between the dynamic space consumed by a vehicle and its speed was established for a case-study of Hanoi, Vietnam by Cao and Sano (2012). Contrary to the space consumption defined in the Paris case by Héran and Ravalet (2008), which employs lane width and reglementary inter-vehicular distance, the dynamic space consumed for the Hanoi case-study developed an empirical model based on traffic videos. This empirical model is used to define dynamic space for vehicles in Rajkot to better account for the mixed road use and predominance of motorized two-wheelers. Motorcycles occupy less space than cars, particularly in both the Indian and Vietnamese contexts as they tend to conglomerate and fit more tightly in the space available. When the LCMP was published (2011), Rajkot did not have public transport buses. Traffic videos analysis on the ground show that under mixed traffic conditions, buses, motorized two-wheelers and rickshaws tend to have similar average speeds (Khanorkar, Ghodmore, \& Khode, 2014; Cao \& Sano, 2012). It is therefore assumed in this paper that bus traffic in year 2031 will have similar speeds than motorized two-wheelers. For pedestrian dynamic space, the work of Fruin (1971) on pedestrian flows is used as a reference. Table 2 summarizes the figures used in this paper.

Table 2. Average speeds in Rajkot and corresponding mean dynamic space per transport mode (Fruin, 1971; Cao \& Sano, 2012) (*adjusted value consistent with ground observation)

\begin{tabular}{lll}
\hline Transport mode & Mean speed $\bar{v}_{x}(\mathbf{k m} / \mathbf{h})$ & Mean dynamic space $\overline{\bar{x}}_{x}\left(\mathbf{m}^{2}\right)$ \\
\hline Car & 22 & 20 \\
Bus & 16 & 55 \\
Auto rickshaw & 16 & 15 \\
Motorized Two-wheeler & 16 & $5.5^{*}$ \\
Bicycle & 11 & 3.9 \\
Pedestrian & 4.7 & 1.4 \\
\hline
\end{tabular}

\subsubsection{Time spent on-road}

The time spend on-road by a specific vehicle is determined by its speed, and the distance travelled, calculated as:

$\mathrm{t}_{\mathrm{ab}}^{\mathrm{x}}=\frac{\mathrm{l}_{\mathrm{ab}}}{\overline{\mathrm{v}_{\mathrm{x}}}}$

Where $l_{a b}$ is the length of road segment $a b, \overline{v_{x}}$ the average speed of mode $x$ on Rajkot and $t_{a b}^{x}$ the time spent on road segment ab for a vehicle of mode $x$ on a day. 


\subsubsection{Space-time consumed on-road in a ward}

The space-time consumed by the total number of vehicles of mode $x$ travelling in the ward $I$, is given by equation (3):

$\alpha_{I}^{x}=\sum_{(a, b) \in I} \overline{s_{x}} \times N_{a b}^{x} \times t_{a b}^{x}$

Where $\alpha_{I}^{x}$ is the space-time consumed by the total number of vehicle of mode $x$ using road segments of ward $I, s_{x}^{-}$is the mean dynamic space consumed by a vehicle of mode $x$ at speed $\overline{v_{\dot{x}}^{-}} N_{a b}^{x}$ is the daily number of vehicles of mode $x$ on road segment $a b$ and $t_{a b}^{x}$ the time spent on road segment ab for a vehicle of mode $x$.
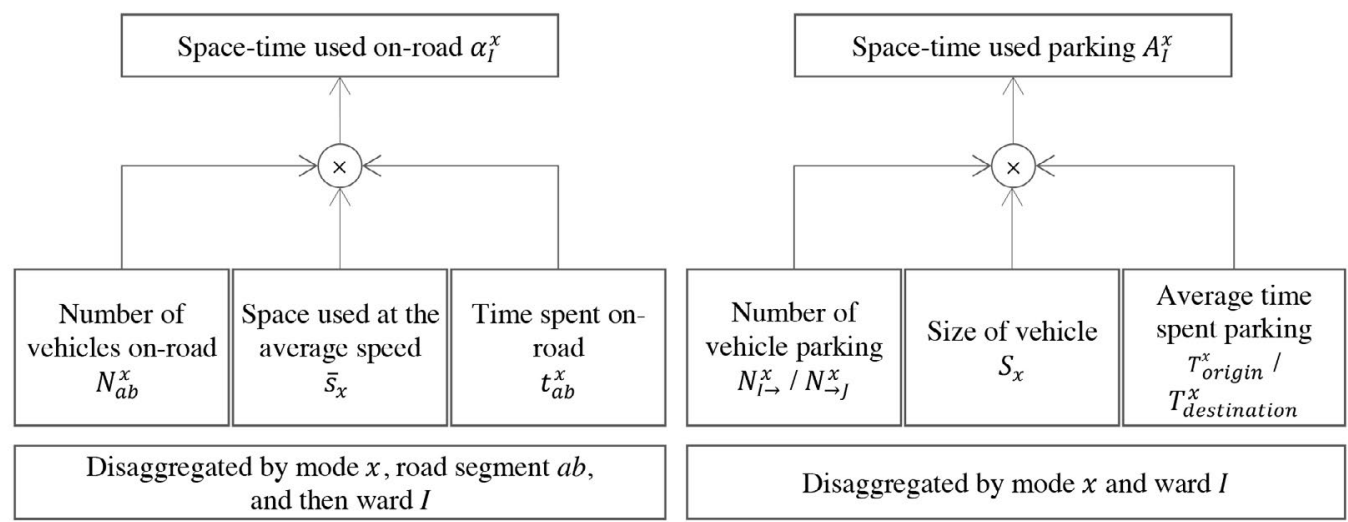

Figure 4. Space-time used on-road (left) and parking (right) calculation methodology

\subsection{Space-time used for parking}

Four main variables define the space-time values used for parking (Figure 4):

- The number of vehicles of mode $x$ parking in the "origin" ward $I$ and "destination" ward $J, N_{I \rightarrow}^{x}$ and $N_{\rightarrow j}^{x}$

- The space used parking by a vehicle of mode $x, S_{x}$

- The time spent parking by vehicles of mode $X$ in the origin and destination ward, $T_{\text {origin }}^{x}$ and $T_{\text {destination }}^{x}$

- The overall space-time consumed by parked vehicles of mode $x$ in the ward $I, A_{I}^{x}$

\subsubsection{Parking space}

The space used for parking vehicles is derived from the Institute for Transportation \& Development Policy (ITDP India) ${ }^{1}$ study (Table 3). Parking time and number of vehicles are computed assuming pendular travelling patterns. The parking dimensions used in this study are on the lower side in com- 
parison to typical parking space allocation in Western cities. For example, in the United Kingdom the typical car parking ${ }^{2}$ size is $6 \mathrm{~m} \times 3.2 \mathrm{~m}$. The values used in this study reflect the ground realities in Indian cities, where vehicles are parked in a compact manner.

Table 3. Average parking dimensions (Institute for Transportation and Development Policy (ITDP))2

\begin{tabular}{llll}
\hline Vehicle type & Average length $(\mathbf{m})$ & Average width $(\mathbf{m})$ & Parking space $\left(\mathbf{m}^{2}\right)$ \\
\hline Car & 5.0 & 2.0 & 10 \\
Bus & 15 & 2.8 & 42 \\
Auto rickshaws & 3.0 & 1.8 & 5.3 \\
Motorized Two-wheelers & 2.0 & 1.0 & 2.0 \\
Bicycle & 2.0 & 0.5 & 1.0 \\
\hline
\end{tabular}

\subsubsection{Cars, motorized two-wheelers, and bicycles: parking time and fleet size}

The parking durations for cars, motorized two-wheelers and bicycles are derived from the mean parking duration at origin (home) and the primary destination as reported in the travel diaries of the household surveys. The parking durations are assumed to be the same for all scenarios. To fit the forecasting framework, and contrary to the parking space consumption methodology developed for the Paris case by Héran and Ravalet (2008), average time values for pendular commuting are used regardless of potential trip chains. The total space-time used for the parking of mode $x$ in the ward $I$ is the sum of the space used by residents' vehicles and vehicles of incoming travelers:

$A_{I}^{x}=S_{x} \times N_{I \rightarrow}^{x} \times T_{\text {origin }}^{x}+S_{x} \times N_{\rightarrow I}^{x} \times T_{\text {destination }}^{x}$

Where $A_{I}^{x}$ represents the space-time used for the parking of mode x in the ward $I, S_{x}$ the space required for the parking of one vehicle of mode $x, T_{\text {home }}^{x}$ the average parking time of mode $x$ (car, twowheelers and bicycles) on a day in the residence location, $T_{\text {destination }}^{x}$ the average parking time of mode $x$ on a day at the primary destination location, $N_{I \rightarrow}^{x}$ the number of vehicles of mode $x$ travelling from the ward $I$ on a day, and $N_{\rightarrow I}^{x}$ the number of vehicles of mode $x$ travelling to the ward $I$ on a day. Equations (5) and (6) show how $N_{I \rightarrow}^{x}$ and $N_{\rightarrow I}^{x}$ have been determined:

$N_{I \rightarrow}^{x}=\sum_{a \in I, \quad b \notin I} N_{a b}^{x}$

$N_{\rightarrow I}^{x}=\sum_{b \in I, \quad a \notin I} N_{a b}^{x}$

Where $N_{a b}^{x}$ is the number of vehicles of mode $x$ on road segment $a b$ in a day.

Contrary to cars, motorized two-wheelers and bicycles, auto-rickshaws and public transport travels are not characterized by daily commuting times and are thus modelled separately.

\footnotetext{
${ }^{1}$ https:/go.itdp.org/display/public/Equivalent+car+space+\%28ECS\%29+conversion+factors

2 https://www.planningni.gov.uk/index/policy/supplementary_guidance/dcans/dcan11_draft/dcan11_draft_design/dcan11_ draft_reserved.htm
} 


\subsubsection{Auto rickshaws and public transport: parking time and fleet size}

Auto rickshaws serve as a substitute for taxis or public transport, and the same vehicle is in operation for several hours per day. The average daily operation time of auto rickshaws is ten hours (Shlaes \& Mani, 2013). The number of auto-rickshaws for the base year is issued from municipal vehicle registration data and adjusted to the projected travel demand for the BAU and LCMP scenarios. An average of six hours of daily operation time is used for buses. The bus fleet size and operation time is from the LCMP project (Munshi et al., 2014).

\section{$4 \quad$ Results}

\subsection{Space-time consumption on-road and parking}

Space-time consumed by transport is expected to triple in the year 2031 if current motorization trends remain (Figure 5). In the LCMP scenario for 2031, space-time used by transport is less than half that of the BAU scenario - with only a marginal increase from today's level. This saving in space-time mainly comes from the LCMP scenario cutting down the use of individual motorized vehicle by enabling a shift to NMT and PT modes, which are low space-time consuming modes.

Parking still accounts for most of the total space-time used by transport in both future scenarios. Due to land use optimization, the average travelling time and trip length are lower in the 2031 LCMP scenario (Table 1), implying a slightly higher parking space-time per vehicle. However, the model shows that the major driver for parking space-time consumption is private automobile use and ownership, which substantially goes down in the 2031 LCMP scenario compared to 2031 BAU scenario, hence reducing parking space-time as a whole.

According to the transport model by Munshi et al. (2014), the shift from individual motorized modes in the BAU scenario to NMT and PT modes in the LCMP scenario does not decrease mobility, as both scenarios stand around 20 million passenger-kilometers travelled per day (Figure 7). In the BAU and base year scenarios, motorized vehicles account for most of the passenger-kilometers travelled as well as most of the space used. In the LCMP scenario, NMT and PT take the higher share of passengerkilometers travelled, but due to their higher spatial efficiency, these modes represent only a small fraction of the space used, indicating an improvement in space efficiency. A comparison of figures 6 and 7 reveals that the space used in proportion to passenger-kilometers travelled is respectively the lowest for buses, followed by pedestrians, bicycles, motorized two-wheelers, and finally cars. This is consistent with previous studies (Héran and Ravalet, 2008).

Even though passenger-kilometers travelled are significantly reduced for cars and motorized twowheelers in the LCMP compared to the BAU scenario, these two modes still amount for a large share of the space used by transport. This high consumption of space is due to parking accounting for most of the total space-time used. This also explains why, when comparing the space used in different scenarios (Figure 6) with passenger-kilometers travelled (Figure 7), a reduction in passenger-kilometers does not always translate in an equivalent space reduction. For example, the $73 \%$ reduction in passenger-kilometers by motorized two-wheelers when shifting from the BAU to LCMP 2031 scenarios is higher than the related space use reduction of $60 \%$ by this mode.

The space consumed by buses in the LCMP 2031 scenario is four times higher than the BAU 2031 scenario, and the space used by NMT modes almost doubles (Figure 6). This is explained by a significant increase in space and infrastructure provided for these modes in the LCMP scenario (Figure 3), as well as the expected increase in bus fleet size (Table 1). The increased mode shares for NMT and PT 
confirm that the dividends of investing in sustainable modes of transport are high.

The issue of transport space distribution equity (or inequity) becomes evident when comparing the space used in different scenarios (Figure 6) with passenger-kilometers travelled by mode (Figure 7). For example, in the LCMP 2031 scenario cars account for $2 \%$ of passenger-kilometers travelled, whereas they represent $32 \%$ of the total transport space used. On the contrary, buses account for $36 \%$ of passenger-kilometers travelled but represent only $5 \%$ of the entire transport space use. While this study does not provide insights on the socio-demographics behind each type of travelers, the method presented here can serve as a basis for this type of social fairness analysis.

Geographically disaggregated values of space-time reductions for Rajkot are shown in Figure 8. The map shows that the shift to low space-time consuming modes in the LCMP scenario decreases the space-time consumed in all parts of the city. In each neighborhood, between 33\% to $75 \%$ of the space can be released by adopting the LCMP scenario compared to the BAU scenario. More space is released in the peripheral areas as the LCMP promotes a compact city development model, where housing, job densities and thus traffic concentrate around central nodes.

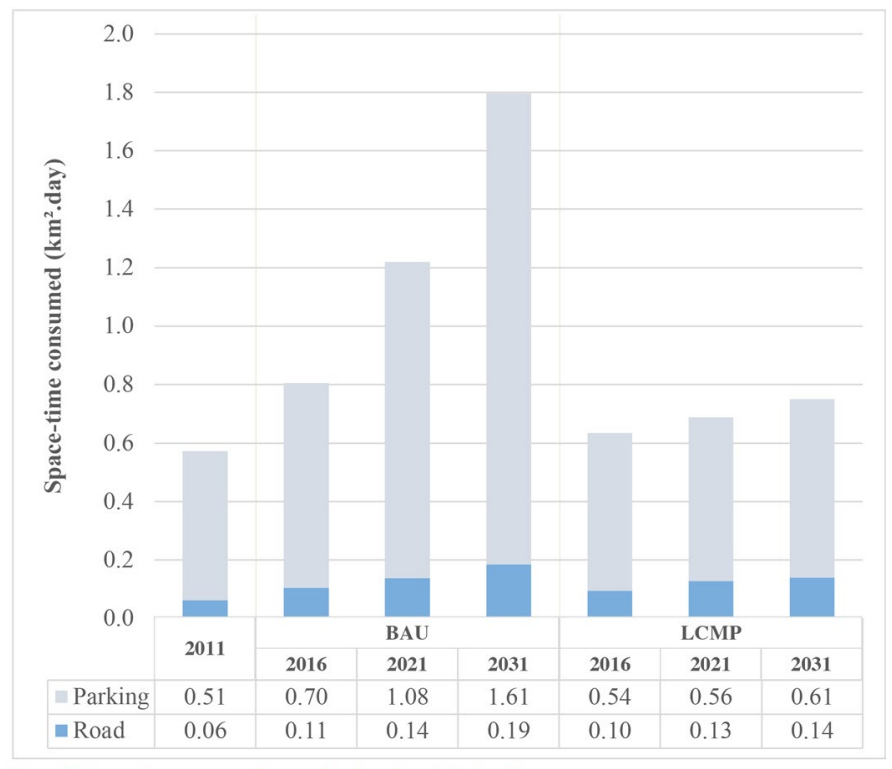

Figure 5. Space-time consumed on-road and parking in Rajkot City 


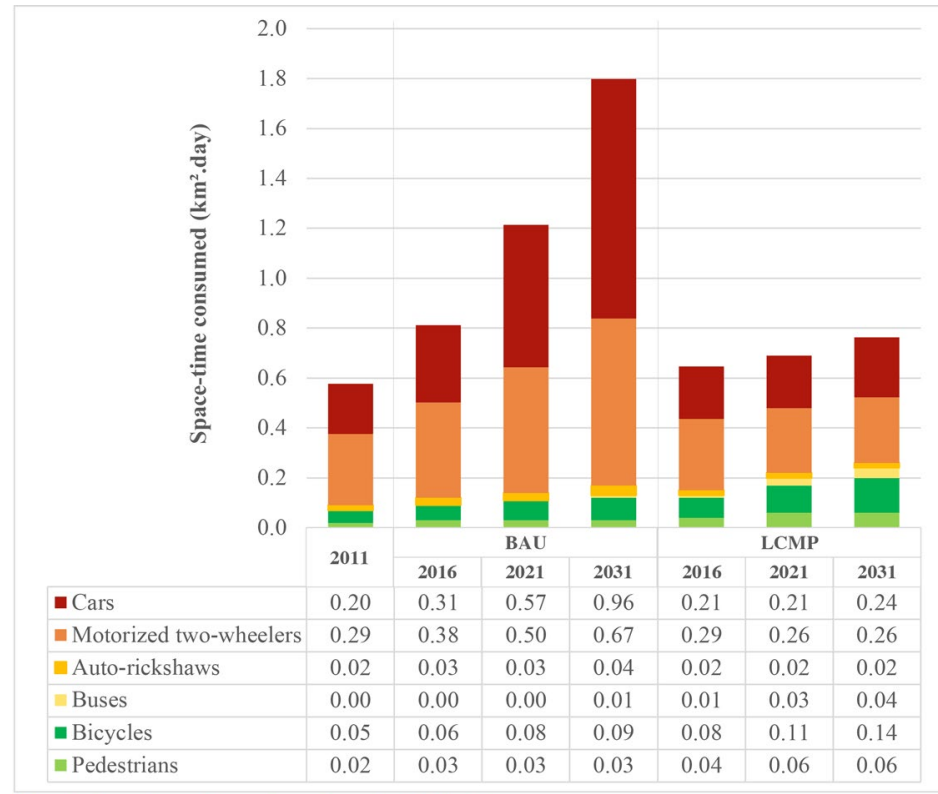

Figure 6. Space-time used by modes and scenarios in Rajkot City

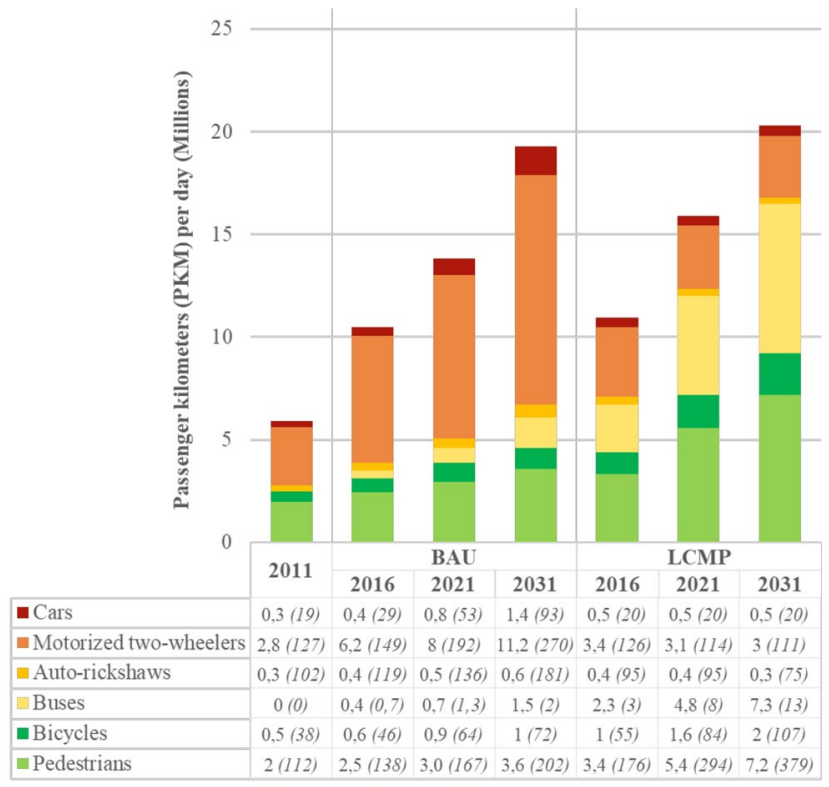

Figure 7. Passengers kilometers travelled by modes and scenarios (millions PKM per day)

In brackets, vehicle numbers for cars, motorized two-wheelers and auto-rickshaws, and number of travelers for bicycle and pedestrians (thousands per day)

Data comes from the LCMP Rajkot report (Munshi et al., 2014) 


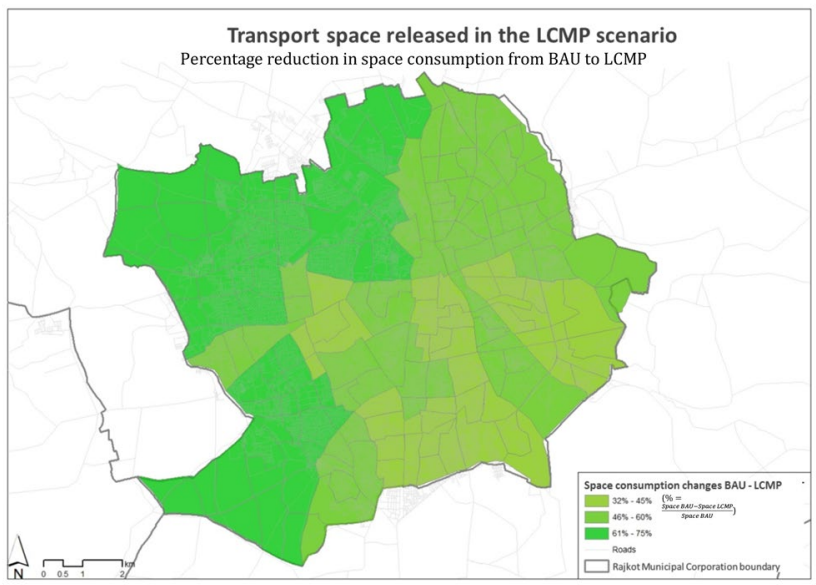

Figure 8. Location of space consumption changes in the low-carbon mobility plan compared to the business-as-usual scenario (percentage reduction in space consumption from BAU to LCMP scenarios) in Rajkot City

\subsection{Space-time occupancy measures: local case study on Raiya road}

Figure 9 and 10 display a demonstration case on Raiya road, one of Rajkot's major axis towards the west of the city. Since demand varies with the time of the day, space consumption on Raiya road is shown both on a daily basis and for the morning peak when road traffic is maximum (9:30 a.m. to 10:30 a.m.). A $1 \mathrm{~km}$-long road section was selected, with a width of $13 \mathrm{~m}$ for year 2011 and $24 \mathrm{~m}$ for year 2031 as per the development scenarios (road sections are illustrated in Figure 9). In the year 2011, the total spacetime available on the stretch in an hour is $13000 \mathrm{~m}^{2} . \mathrm{hr}$, and $312000 \mathrm{~m}^{2} . \mathrm{hr}$ on a daily basis. Similarly, in year 2031, the total space-time available on the stretch in an hour is $24000 \mathrm{~m}^{2} . \mathrm{hr}$, and $590000 \mathrm{~m}^{2} . \mathrm{hr}$ on a daily basis.

In this demonstration case, the mean dynamic spaces used are those presented in Table 2. For the daily space-time calculation, the average speeds in Rajkot are also those presented in Table 2 . For the peak hour analysis, a congested speed of $10 \mathrm{~km} / \mathrm{h}$ is used, in accordance with the speed-flow graph for Raiya road's capacity (Rahimi, 2018, pp457, Figure 7). In contrast with the daily city-wide analysis where results in Figure 6 were shown in $\mathrm{km}^{2}$.day, results for this case are given in $\mathrm{m}^{2}$.hr to fit with the smaller overall scale.

With those parameters, the daily space consumption on the stretch stays below the daily space supply for all transport development scenarios, with consumption rates varying between $15 \%$ and $38 \%$ depending on the scenario.

However, space pressure intensifies in peak hour. The peak hour traffic space consumption on the stretch in 2011 occupies $65 \%$ of the total road space available. Although it could be expected that almost $100 \%$ of the available road space be used under congested conditions, factors such as mixed traffic and unused road space at intersections contribute to a lower space-time consumption rate even in perceived congestion. As a comparison, Héran and Ravalet (2008) found an average road space occupation of around $20 \%$ in peak hour over the whole city of Paris, perhaps lower than what one would have heuristically estimated.

If development was to happen following the BAU scenario, the peak hour space demand would exceed supply by $100 \%$, despite the forecasted road widening from $13 \mathrm{~m}$ to $24 \mathrm{~m}$. This demand is mostly driven by cars and motorized two-wheelers. These numbers indicate that city managers might have to 
plan for another doubling of space allocated to road traffic to counter congestion.

If the LCMP scenario were to be implemented, peak hour demand is still high, amounting to $88 \%$ of the planned supply. This rate is nevertheless more than two times lower than in the BAU situation while keeping a similar level of passenger-kilometers than the BAU scenario (Figure 7) thanks to prioritizing space-efficient modes such as buses.

Raiya road is only a demonstration case: a similar situation can be expected across the city, indicating the need for incorporating measures that encourage mobility solutions that utilize less urban space.
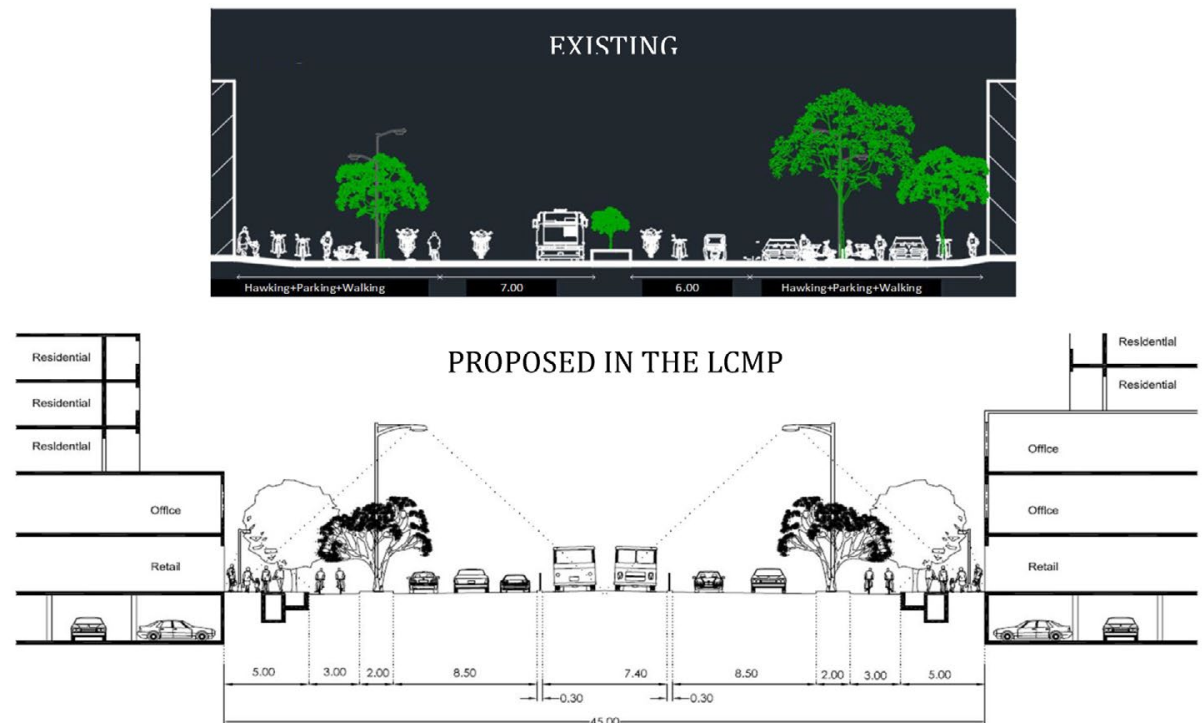

Figure 9. Existing infrastructures for Rayia Road, Rajkot, and proposed infrastructures in the LCMP (road dimensions are in meters)

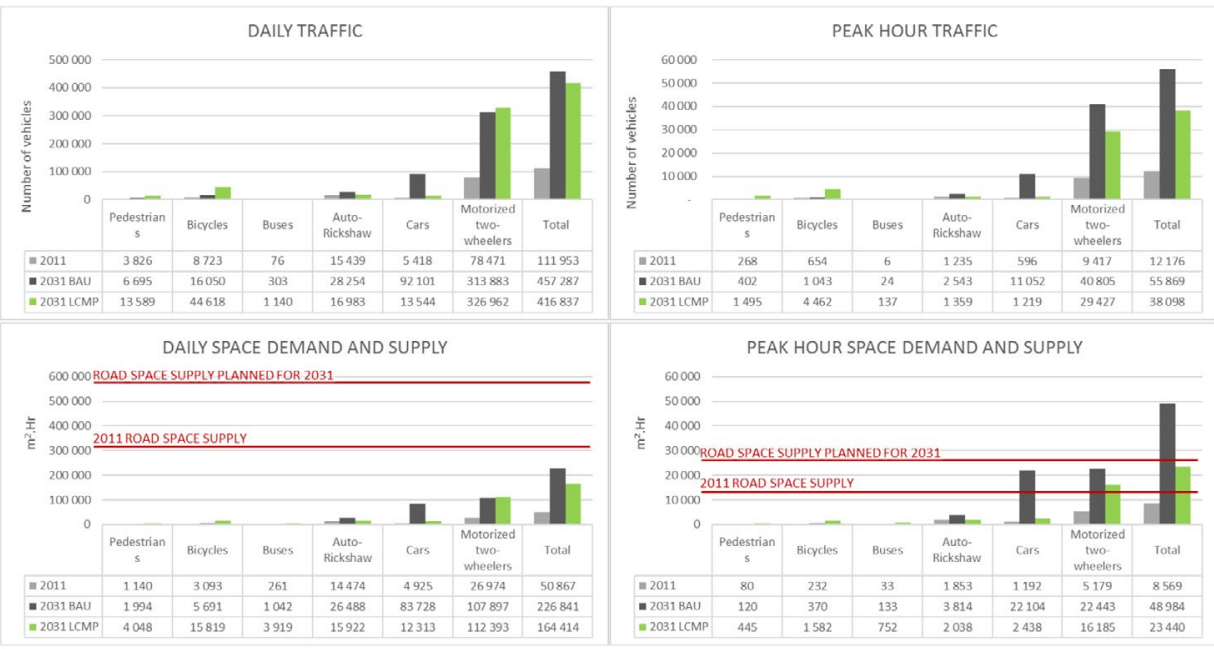

Figure 10. Space-time demand and supply on Raiya Road, Rajkot 


\section{$5 \quad$ Limitations and future research}

The methods presented here could be further improved by incorporating actual travelling speeds instead of average speeds, which would account more precisely for the effect of congestion and potentially affect the travelling time calculations used in the traffic models for all future scenarios. The dynamic space based on the speed by mode uses the values from Cao and Sano (2012), which may also gain from a more precise and empirically derived values for the Indian context, especially for motorcycles. The parking fleet size considers travelling vehicles only, inferring that there are no more vehicles than the ones used daily, which may underestimate the actual number of parked vehicles. The rapid development of ride hailing in recent years might also impact transport space consumption, in favor this time of a lower car ownership and thus space use. The results of the baseline year are validated by looking at the road occupancy measures calculated by the model, which are comparable to those calculated in the Paris case study by Héran and Ravalet (2008) who used similar vehicle size parameters.

As for future research, a comprehensive spatial assessment could also include an "energy footprint" resulting from urban transports. For example, Chi and Stone (2005) propose an energy footprint calculation methodology, and de Nazelle et al. (2012) defined a transport "ecological footprint". These approaches add together the transport system's actual physical footprint, which is the total space allocated to transport in the city, and its equivalent "spatial energy footprint", which is the equivalent forestry land required to absorb (and therefore offset) transport-related direct and indirect CO2 emissions. Wackernagel and Rees (1996) estimated that indirect carbon emissions from road construction and maintenance are equivalent to about $45 \%$ of the total annual fuel consumed by vehicle travel. Therefore, it is likely that a more holistic spatial assessment including both the physical and ecological footprint would further disadvantage individual motorized pathways of development.

\section{Conclusions}

There is little empirical evidence available in the scientific literature on the combination of time and space used by different transport modes, which is particularly relevant in urban contexts where space is limited. The objective of this paper was to investigate space-time consumption and assess whether investments in non-motorized transport (NMT) and public transport (PT) lead to more efficient and sustainable transport space planning and infrastructure provision. The analysis builds on the transport model developed for Rajkot City by the UNEP project "Promoting Low Carbon Transport."

In doing so, this paper presents a methodology to quantify space used by modes through time. The space-time consumed by vehicles while travelling on-road and when parked give an indication of the differential space consumption between modes. It is clear from the work presented here that for the case of the city of Rajkot, individual motorized vehicles consume a significant proportion of road and parking space but provide mobility to only a few. On the contrary, walking, bicycle and buses (in the year 2031) could provide mobility to a large section of the population while consuming significantly less physical road space.

In dense urban settings like in Rajkot, physical road space is scarce, and policies should therefore aim for optimal use. Road infrastructure expansion typically focuses on increasing capacity and speeds for individual motorized modes, but meeting new motorized demands for road space also generates induced traffic and locks in long-term urban sprawl and car dependency. This research shows that this approach is not a sustainable option in terms of space use. The low carbon mobility plans prepared for 
the city of Rajkot show that if adequate and adequately designed infrastructure is provided for NMT, existing NMT mode users could be retained and new users could be attracted. The evolution of the physical road space consumed (Figure 4) shows high levels of mobility can be provided with NMT and PT modes while reducing the overall transport spatial footprint, thus improving overall spatial efficiency. These results should prompt a radical shift of focus to allocating more space to non-motorized and public transport as a key ingredient in avoiding future congestion.

In light of this, the first practical implications for city administrators and planners is to add modal road space consumption to their basket of key indicators when assessing passenger transport efficiency and urban traffic in general. What gets measured gets done, but conventional transport models typically lack a multimodal spatial perspective. Therefore, recognizing that space allocation is a key variable in constrained urban spaces is a first step to recognizing the opportunity cost associated with space use. Yet it is not new that pedestrians or cyclists or buses use less space per passenger-kilometer. Cities also face very real political practicalities when formulating policies aiming at reallocating or reducing road space to be used by cars, which brings forth the issue of spatial and transport equity: not only what modes, but who gets to use the space also matters. Depending on their regular mode of transport, various socioeconomic groups use more or less space, and therefore the approach proposed here can also be used to uncover hidden transport injustices. In other words, a space footprint indicator correlated to socioeconomic groups may help to make visible structural unfairness in the system and hold administrations accountable for the impact of their decisions on those who typically do not have a voice e.g. the poor, women, or children.

In conclusion, the approach presented here draws attention towards differential space-time consumption by transport modes. This approach can be used by urban and transport planners to consider the issue of road space consumption in future transport infrastructure assessment and make informed decisions in terms of road space allocation, which brings important implications and potential synergies with issues of equity, particularly in terms of spatial and transport justice. 


\section{References}

Apel, D. (2000). Traffic system, space demand and urban structure. Velo Mondial, Amsterdam.

Banister, D. (2008). The sustainable mobility paradigm. Transport Policy, 15, 73-80. https://doi. org/10.1016/j.tranpol.2007.10.005

Banjo, G., \& Dimitriou, H. (1983). Urban transport problems of third world cities: The third generation. Habitat International, 7(3-4), 99-110.

Cao, K., \& Sano, T. V.T. (2012). Estimating capacity and vehicle equivalent unit by motorcycles at road segments in urban road. Journal of Transportation Engineering, 138, 776-785.

Chi, G., Stone Jr, B. (2005). Sustainable transport planning: Estimating the ecological footprint of vehicle travel in future years. Journal of Urban Planning and Development 131(3),170-181. https:// doi.org/10.1061/?ASCE?0733-9488?2005?131:3?170? CE

de Nazelle, A., Fruin, S., Westerdahl, D., Martinez, D., Ripoll, A., Kubesch, N., \& Nieuwenhuijsen, M. (2012). A travel mode comparison of commuters' exposures to air pollutants in Barcelona. Atmospheric Environment 59, 151-159. https://doi.org/10.1016/j.atmosenv.2012.05.013

Dimitriou, H. T. (2006). Towards a generic sustainable urban transport strategy for middle-sized cities in Asia: Lessons from Ningbo, Kanpur and Solo. Habitat International, 30(4), 1082-1099. https:// doi.org/10.1016/j.habitatint.2006.02.001

Drut, M. (2018). Spatial issues revisited: The role of shared transportation modes. Transport Policy, 66, 85-95. https://doi.org/10.1016/j.tranpol.2018.02.003

Fruin, J. (1971). Pedestrian planning and design (Metropolitan edition). New York: Metropolitan Association of Urban Designers and Environmental Planners.

Geurs, K. T. (2006). Accessibility, land use and transport (Uitgeverij edition). Delft, Netherlands: Uitgeverij Eburon.

Gössling, S., Schröder, M., Späth, P., Freytag, T., Gössling, S., Schröder, M., ... \& Freytag, T. (2016). Urban space distribution and sustainable transport. Transport Reviews, 36, 659-679. https://doi.org /10.1080/01441647.2016.1147101

Héran, F., \& Ravalet, E. (2008). La consommation d' espace-temps des divers modes de déplacement en milieu urbain Application au cas de l' Ile de France 1-188.

Hickman, R., Ashiru, O., \& Banister, D. (2011). Transitions to low-carbon transport futures: Strategic conversations from London and Delhi. Journal of Transport Geography, 19, 1553-1562.

Khanorkar, A. R., Ghodmare, S. D., \& Khode, B. V. (2014). Impact of lane width of road on passenger car unit capacity under mix traffic condition in cities on congested highways. International Journal of Engineering, 4, 180-184.

Kivimaa, P., \& Virkamäki, V. (2014). Policy mixes, policy interplay and low carbon transitions: The case of passenger transport in Finland. Environment Policy and Governance, 24, 28-41.

Metz, D. (2008). The myth of travel time saving. Transport Reviews 28, 321-336. https://doi. org/10.1080/01441640701642348

MOUD. (2006). National urban transport policy. New Delhi: Government of India.

Munshi, T. (2013). Built form, travel behavior and low carbon development in Ahmedabad, India. Enschede, Netherlands: University of Twente.

Munshi, T., \& Brussel, M. (2004). Use of geo-information to determine the work place accessibility using public transport in Ahmedabad City, India. In Proceedings of CUPUM 05, Computers in Urban Planning and Urban Management, 30-Jun-2005, London. (14 p.).

Munshi, T., Maarseveen, M. F. A. M., \& van Zuidgeest, M. H. P. (2013). Built form, travel behavior and low carbon develpment in Ahmedabad, India. Enschede, Netherlands: University of Twente. 
Munshi, T., Shah, K., Vaid, A., Sharma, V., Joy, K., Roy, S., .. \& Joseph, Y. (2014). Low-carbon comprehensive mobility plan: Rajkot. Denmark: UNEP DTU Partnership.

Munshi, T., \& Zia-ul-Haque, J., Y. (2016). Examining equity in spatial distribution of recreational and social infrastructure in Delhi. In S. S. Acharya, S. Sen, M. Punia, \& S. Reddy (Eds.), Marginalization in globalizing Delhi: Issues of land, livelihoods and health. New Delhi: Springer. https://doi. org/10.1007/978-81-322-3583-5_6

Nello-Deakin, S. (2019). Is there such a thing as a "fair" distribution of road space? Journal of Urban Design, 24, 698-714. https://doi.org/10.1080/13574809.2019.1592664

Oldenziel, R., \& Albert de la Bruhèze, A. (2011). Contested spaces. Transfers, 1, 29-49. https://doi. org/10.3167/trans.2011.010203

Pucher, J., Korattyswaropam, N., Mittal, N., \& Ittyerah, N. (2005). Urban transport crisis in India. Transport Policy, 12, 185-198.

Rahimi, M. R. (2018). Estimation of capacity and level of service for four-lane divided urban arterial road. International Journal for Research in Applied Science and Engineering Technology, 6, 452-459. https://doi.org/10.22214/ijraset.2018.4079

Shlaes, E., \& Mani, A. (2013). A case study of the auto-rickshaw sector in Mumbai. Transportation Research Record, 2416(1) 56-63.

Shoup, D. (2006). Cruising for parking. Transport Policy, 13, 479-486. https://doi.org/10.1016/j.tranpol.2006.05.005

Tiwari, G. (2011). Key mobility challenges in Indian cities. Paper presented at the International Transport Forum, Leipzig, Germany.

Unruh, G. C., \& Carrillo-Hermosilla, J. (2006). Globalizing carbon lock-in. Energy Policy, 34, $1185-$ 1197.

Von Schönfeld, K. C., \& Bertolini, L. (2017). Urban streets: Epitomes of planning challenges and opportunities at the interface of public space and mobility. Cities, 68, 48-55. https://doi.org/10.1016/j. cities.2017.04.012

Wackernagel, M., \& Rees, W. (1996). Our ecological footprint: Reducing human impact on the earth. Philadelphia: New Society Publishers.

Wegener, M., \& Fürst, F. (1999). Land-use transport interaction: State of the art. Retrieved from https:// doi.org/10.2139/ssrn.1434678 